\title{
Identifikasi lapisan akuifer menggunakan metode geolistrik konfigurasi wenner di daerah kering desa Kalitengah kecamatan Panggungrejo kabupaten Blitar
}

\author{
Naftalia Qisthi, Daeng Achmad Suaidi*, Sujito \\ Universitas Negeri Malang, Jl. Semarang No. 5 Malang, Jawa Timur, Indonesia \\ *Penulis korespondensi, Surel: daeng.achmad.fmipa@um.ac.id
}

Paper received: Paper received: 01-01-2022; revised: 15-01-2022; accepted: 31-01-2022

\begin{abstract}
Kalitengah Village, Kecamatan Panggungrejo, Kabupaten Blitar is a lack of ground water place, most of it is karst area. In dry season, villagers had to do hard work to find clean water source. They even have to buy it from another place. it was happened because not all of their well produces adequate amount of clean water. This research purposed to get information about spread and depth of the aquifer layer in Kalitengah Village, KecamatanPanggungrejo, Kabupaten Blitar in order to make new source of clean water. By using value of rock resistivity and subsurface structure information, clean water source can be located. The method of this research is geo-electrical wenner configuration with sounding technique. One point of sounding applied at known well as reference, and 25 points of sounding with $5 \mathrm{~m}$ separation as guess mapping the presence of subsurface aquifer. Acquisition have done by locate the current and potential electrodes position. Then, the current was injected until value of apparent resistivity appeared. These processes repeated until the entire area has been mapped.The result showed the subsurface resistivity value of research area. The resistivity of ground water in reference sounding point is $28-32 \mathrm{Ohm}$-meters and found in $15 \mathrm{~m}$ below the surface. in sounding point 1-20, there is no presence of ground water aquifer. Interpretation on the result of software ZondRes2D shows resistivity value less than $28-32 \mathrm{Ohm}$-meters. The resistivity of ground water in reference sounding point is $28-32 \mathrm{Ohm}$-meters and found in $15 \mathrm{~m}$ below the surface. Aquifer layer found at point $1-25$ with dept about 7, $25-18,5 \mathrm{~m}$, interpretation on the result of software ZondRes $2 \mathrm{D}$. The aquifer became thicker from sounding point 1 to 25 and from 3D section showed the spread of aquifer is tend to south and west.
\end{abstract}

Keywords: Aquifer; Geoelectrical method; Wenner Configuration; ZondRes2D

\section{Pendahuluan}

Air merupakan salah satu kebutuhan pokok bagi makhluk hidup di bumi yang harus terpenuhi. Kebutuhan akan air semakin meningkat baik untuk memenuhi kebutuhan manusia secara langsung sebagai bahan baku air minum dan memasak maupun secara tidak langsung seperti untuk pertanian maupun peternakan. Semakin meningkatnya kebutuhan air, maka di sisi lain ketersediaannya justru semakin menurun. Oleh karena itu perlu adanya pencarian sumber air baru yang berpotensi berupa akuifer. Menurut Syuhada, 2013, akuifer ini terdapat dalam suatu lapisan tanah berpori yang mengakibatkan aliran air dalam tanah. Air dalam tanah ini bergerak baik secara vertikal maupun lateral yang dipengaruhi oleh keadaan geologi, morfologi dan hidrologi daerah setempat. Adapun parameter fisika yang ditentukan dalam karakterisasi akuifer ini pada umumnya adalah konduktivitas hidraulik, kedalaman dan transmisivitas akuifer.

Sumber air merupakan kebutuhan yang sangat penting, namun tidak semua daerah memiliki sumber air yang dapat memenuhi kebutuhan manusia. Di daerah kering Desa Kalitengah, Kecamatan Panggungrejo, Kabupaten Blitar, debit air dari sumber mata air dan sungai sudah tidak dapat mencukupi kebutuhan masyarakat. Kondisi yang semacam ini menjadikan masyarakat mengandalkan sumber air yang lumayan jauh dari pemukiman warga. 
Saat musim kemarau, debit air pada sumber air yang ada akan semakin kecil. Hal ini mempersulit masyarakat dalam memperoleh air bersih. Desa Kalitengah merupakan salah satu dari 36 desa yang terancam rawan kekeringan (BPBD, 2013).

Suwari, warga Desa Kalitengah menyampaikan "banyak warga di desa ini kesulitan untuk mencari air bersih. Saat musim kemarau warga terpaksa berjalan cukup jauh untuk mendapatkan air atau membeli air dengan harga yang cukup tinggi".

Secara tradisional, cara yang lazim dan banyak digunakan adalah dengan menggunakan uji pompa atau "pumping test" dari suatu sumur dimana akuifer tersebut berada. Namun, cara ini tidak akan efektif dalam menentukan distribusi sebaran kondisi akuifer suatu wilayah karena akan memerlukan beberapa sumur baru yang tentunya akan memerlukan waktu dan biaya yang tidak sedikit. Sehingga telah dikembangkan pula metoda yang cukup efektif dan murah untuk menentukan parameter akuifer misalnya dengan menggunakan data vertical electric sounding berupa resistivitas dari suatu lapisan formasi batuan penyusun akuifer (Syuhada, 2013).

Metode geolistrik Tahanan Jenis (Resistivity) adalah salah satu metode geofisika yang bisa digunakan memetakan resistivitas bawah permukaan. Hal ini dimungkinkan karena lapisan tanah dan batuan yang terisi air sangat mudah mengalirkan arus listrik atau bersifat konduktif. Lapisan tanah yang seperti ini biasanya memiliki harga resistivitas tertentu (nilai resitivity rendah). Dengan menampilkan penampang resistivitas bawah permukaan hasil pengukuran geolistrik metode resistivity maka dapat diprediksikan lapisan-lapisan tanah atau batuan yang tersaturasi air, sehingga dapat memprediksi lokasi dan kedalaman tempat lapisan tanah yang mengandung air tawar yang baik untuk pengairan daerah tersebut (Sultan, 2009). Metode golistrik resistivitas sudah digunakan untuk identifikasi air tanah di berbagai tempat, antara lain : Gushigeu dan Karaga, Ghana Utara (Asare, 2013), Cuddalore, Tamilnadu, India (Chidambaram, 2013), dan Obubra Selatan, Nigeria Tenggara (Odong, 2013).

Berdasarkan permasalahan diatas, maka diperlukan penelitian mengenai kondisi sumber air di Desa Kalitengah Kecamatan Panggungrejo Kabupaten Blitar untuk menentukan letak sumber air untuk memenuhi kebutuhan masyarakat, yaitu "Penentuan Akuifer Menggunakan Metode Geolistrik Konfigurasi Wenner di Daerah Kering Desa Kalitengah Kecamatan Panggungrejo Kabupaten Blitar".

Dalam penelitian ini, digunakan metode geolistrik konfigurasi Wenner untuk menggambarkan penyebaran tahanan jenis bawah permukaan dengan mempelajari sifat aliran listrik di dalam bumi dengan cara mendeteksinya di permukaan. Perbedaan tahanan jenis di lapangan itulah yang menggambarkan beragamnya lapisan batuan yang ada. Data hasil selanjutnya diolah dengan software ZondRes2D untuk kedalaman dan ketebalan lapisan air tanah.

\section{Tujuan penelitian}

1. Menentukan kedalaman akuifer bawah permukaan di Desa Kalitengah Kecamatan Panggungrejo Kabupaten Blitar.

2. Menentukan sebaran akuifer bawah permukaan di Desa Kalitengah Kecamatan Panggungrejo Kabupaten Blitar. 


\section{Metode}

Penelitian ini merupakan penelitian lapangan dimana peneliti melakukan pengambilan data langsung pada tempat yang akan diteliti.peneliti melakukan pengambilan data di Desa Kalitengah, Kecamatan Panggungrejo Kabupaten Blitar. Penelitian ini dilakukan menggunkan alat Geolistrik Oyo type McOhm-El model-2219d. Diawali dengan survey pustaka yang kemudian dilanjutkan dengan survey lapangan, pengambilan data lapangan, pengolahan data hasil penelitian dan dilanjutkan dengan prosesing data terolah. Pada penelitian ini menggunakan metode geolistrik dengan konfigurasi wenner. Pengolahan data dilakukan menggunkan software Ms excel, note pad, dan ZondRes2D

\subsection{Lokasi penelitian}

Lokasi penelitian berada di Desa Kalitengah Kecamatan Panggungrejo Kabupaten Blitar yang terletak sekitar $12 \mathrm{~km}$ di selatan kota Blitar.

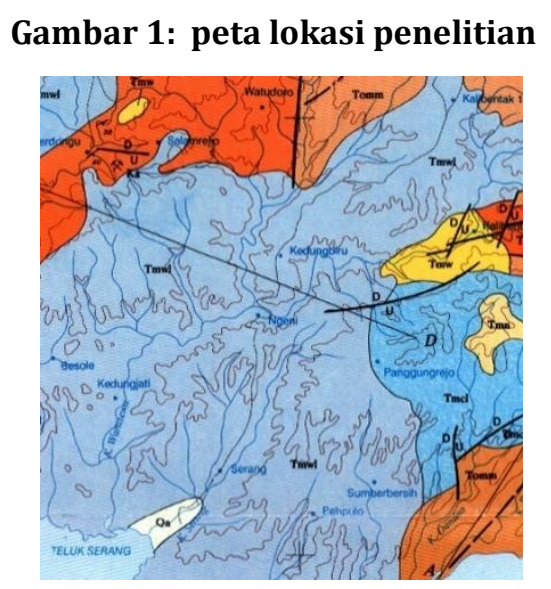

Pengambilan data dilakukan dengan satu titik sounding sebagai data acuan, dan 25 titik sounding sebagai pemetaan dengan jarak 5m tiap titiknya.

\subsection{Prosedur penelitian}

2.2.1. Prosedur penelitian dengan menggunakan konfigurasi wenner yaitu :

2.2.2. Menyiapkan skema pemetaan dan peralatan yang digunakan.

2.2.3. Mengukur lintasan yang akan dilakukan pengukuran, dengan membuat jarak spasi 5 dengan rentang $150 \mathrm{~m}$ untuk data sumur dan $105 \mathrm{~m}$ untuk data pemetaan.

2.2.4. Merangkai alat sesuai dengan konfigurasi wenner.

2.2.5. Mengaktifkan alat resitivity.

2.2.6. Menginjeksikan arus kedalam bumi melalui dua elektroda dan juga potensialnya. Dipasangkan kabel-kabel pada konfigurasi elektroda. Dua kabel sebagai elektroda arus dan dua kabel sebagai elektroda potensial sesuai dengan konfigurasi wenner.Mencatat arus listrik (i), potensial diri (V) dan nilai resitivitas (R). 
Data diolah menggunkan ms Excel, notepad, dan terahir diinversi menggunakan software ZondRes2D

\section{Hasil dan Pembahasan}

\subsection{Analisis Data}

Dari data pengukuran dan perhitungan di atas kemudian diinterpretasikan menggunakan Software ZondRes2D sehingga dapat dilihat struktur batuan di zona tersebut. Langkah-langkahnya sebagai berikut:

3.1.1. Data kita akan interpretasi ditulis kedalam bentuk DAT.FILE

\subsubsection{Menjalankan program ZondRes2D}

3.1.3. File >> Open File yaitu perintah untuk membaca file yang berisi data yang telah disimpan dalam bentuk file.dat.

3.1.4. Mesh constructor yaitu perintah untuk mengatur kedalaman jangkauan.

3.1.5. Klik cancel jika muncul kotak dialog "very large number of parameters!"

\subsubsection{D >> Start inversion}

3.1.7. Option >> Model >> Contour-section yaitu perintah untuk menampilkan gambar parameter pelapisan bawah permukaan

3.1.8. Untuk mendapatkan sebaran akuifer, peneliti menjelaskan pola-pola yang ada pada gambar.

\subsection{Analisis Data Sumur}

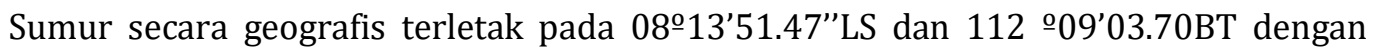
elevasi 329m.

\section{Gambar 2. Hasil interpretasi data pengukuran resistivitas dengan ZondRes2D}

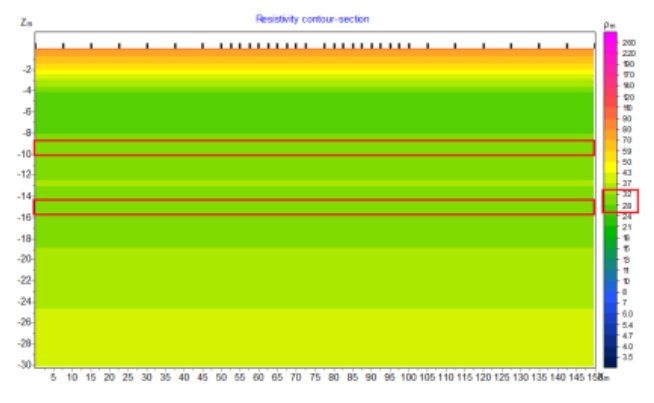

Berdasarkan hasil pengambilan data lapangan diketahui bahwa kedalaman sumur acuan 8,40m. Dari hasil olahan data software ZondRes2D, digambarkan dengan warna hijau terlihat bahwa bagian tersebut memiliki nilai resitivitas antara 28-32 $\Omega$. Menurut keterangan warga kedalaman sumur saat digali sekitar $15 \mathrm{~m}$, pada gambar 4.2 diketahui memiliki resistivitas antara 28-32 $\Omega$ yangsesuai dengan teori bahwa air tanah memiliki rentang resistivitas antara 10-100. Dapat dipastikan bahwa bagian tersebut merupakan air tanah. 


\subsection{Analisis Titik Sounding}

Setiap titik sounding diinterprestasikan dengan menggunakan software ZondRes2D.

\subsection{Analisis 3D}

Setelah dilakukan analisis setiap titik sounding, selanjutnya titik-titik sounding digabungkan untuk mendapatkan analisis 3D. berikut merupakan hasil inversi 3D:

\section{Gambar 3. Hasil interpretasi 3D}

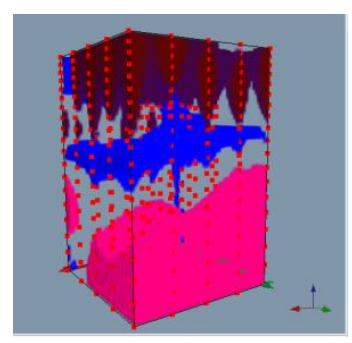

Berdasarkan analisis 3D dapat diketahui dugaan pola persebaran akuifer dibawah permukaan tanah akuifer menyebar kearah selatan dan timur. Seperti yang telihat pada Gambar 3, semakin ke selatan dan timur maka akuifer akan semakin dalam.

\section{Simpulan}

\subsection{Kesimpulan}

Berdasarkan pembahasan dapat disimpulkan bahwa.

4.1.1. Titik sounding sumur yang digunakan sebagai data acuan memiliki nilai resistivitas 28$32 \Omega$ di kedalaman $15 \mathrm{~m}$. Lapisan akuifer terdapat pada titik sounding ke $1-25$ dengan kedalaman antara 9, 25 - 28 meter.Dari titik 1 ke titik 25 ketebalan lapisan akuifer bertambah tebal.

4.1.2. Dugaan sebaran akuifer adalah kearah selatan dan timur dari titik sounding 1-25 dengan jarak kurang lebih $1100 \mathrm{~m}$ dari sumur acuan.

\subsection{Saran}

4.2.1. Berdasarkan penelitian yang telah dilakukan, maka ada beberapa hal yang perlu diperhatikan, yaitu.

4.2.2. Penelitian dilakukan dengan lintasan yang lebih panjang agar mendapatkan gambaran bawah permukaan yang lebih dalam dan mennambah titik sounding agar mendapatkan luasan yang lebih maksimal.

4.2.3. Dilakukan penelitian lanjutan berupa pemboran pada titik-titk sounding yang di duga terdapat akuifer untuk membuktikannya. 


\section{Daftar Rujukan}

Asare, V. D. S., \& Menyeh, A. (2013). geo-electrical investigation of groundwater resources and aquifer characteristics in some small communities in the gushiegu and Karaga districts of Northern Ghana. International Journal of Scientific \& Technology Research, 2, 25-35.

Badan Penanggulangan Bencana Daerah Kabupaten Blitar. (2014, Agustus 24). 36 Desa Di Kab Blitar terancam Rawan Kekeringan. www.blitarkab.go.id/2013/09/8932.html

Chidambaram Chidambaram, S. (2013). Identification of groundwater potential zone by using GIS and electrical resistivity techniques in and around the Wellington reservoir, Cuddalore district, Tamilnadu, India. European Scientific Journal, 9(17).

Odong, P. O. (2013). Groundwater potential evaluation and aquifer characterization using resistivity method in Southern Obubra, Southeastern Nigeria. International Journal of Environmental Sciences, 4(1), 96105.

Santoso, D. (2002). Pengantar teknik geofisika. Bandung: ITB, 99-110.

Sari, S. A. (2011). Identifikasi zona lemah karena intrusi air dengan metode geolistrik konfigurasi wenner (Studi kasus desa Joho Kecamatan Kalidawir Kabupaten Tulungagung) (Doctoral dissertation, Universitas Negeri Malang).

Sultan. (2009). Penyelidikan Geolistrik Resistivity pada Penentuan Titik Sumur Bor untuk Pengairan di Daerah Garongkong Desa Lampang Kecamatan Tanete Riaja Barru,12 (2). http://puslit2.petra.ac.id/ejournal/index.php/enjiniring/article/view/17846

Syuhada. \& Anggriono, T. (2013). Penentuan Transmisivitas Akuifer di Daerah Padarincang dengan Menggunakan Data Geolistrik Sounding, 31 (1). www.fisika.lipi.go.id 